\title{
Bifocal Patellar Tendon Avulsion Fractures in Children and Adolescents: Diagnosis and Treatment Considerations for a Unique Injury Pattern
}

\author{
Sreetha Sidharthan, M.D., Lindsay M. Schlichte, M.S., Daniel W. Green, M.D., M.S., \\ David M. Scher, M.D., and Peter D. Fabricant, M.D., M.P.H.
}

\begin{abstract}
Purpose: To highlight important diagnostic and treatment considerations in patients who present with bifocal patellar tendon avulsion fractures from the tibial tubercle and inferior patellar pole. Methods: Radiographic presentation, surgical technique, and complications of 5 children who sustained bifocal patellar tendon avulsion fractures with $\geq 6$ months postoperative follow-up were retrospectively reviewed. Hospital for Special Surgery (HSS) Brief Functional Activity Scale (HSS Pedi-FABS), Patient-Reported Outcomes Measurement Information System (PROMIS) pain interference, PROMIS mobility, and Pediatric International Knee Documentation Committee Scale (Pedi-IKDC) were assessed at most recent follow-up. Results: Five children (4 boys, 1 girl) presented with bifocal patellar tendon avulsion fractures with a median follow-up of 12.8 months (range 7.7 to 26.4). In 1 case, advanced imaging was not pursued, and the bifocal nature of injury was subsequently discovered intraoperatively. In all other cases, magnetic resonance imaging (MRI) correctly characterized the bifocal injuries and revealed the full extent of fractures and soft tissue injury. Surgical management involved suture anchor repair with heavy nonabsorbable sutures. Postoperative functional and patient-reported outcomes were within the range of population healthy/normative values (for those that were available for comparison, e.g., PediIKDC), and clinically relevant improvement was noted when comparing preoperative and postoperative patient-reported outcome measures of both pain and mobility. Conclusions: Advanced imaging (e.g., MRI) is required to understand the full extent of injury and should be obtained in the setting of traumatic patella alta to evaluate for the presence of a bifocal lesion and plan surgical intervention accordingly. These patients demonstrate satisfactory functional and patient-reported outcomes after operative repair. Level of Evidence: IV, therapeutic case series.
\end{abstract}

A vulsion fractures of the tibial tubercle represent $<1 \%$ of apophyseal injuries in the pediatric population. ${ }^{1,2}$ These fracture patterns are most common in male adolescents, typically between the ages of 13 and 16 years. $^{1}$ The mechanism of injury involves high tensile force at the attachment of the patellar tendon to the tibial apophysis due to a violent quadriceps contraction. ${ }^{3}$ Avulsion fractures from the inferior

\footnotetext{
From the Division of Pediatric Orthopaedic Surgery, Hospital for Special Surgery, New York, NY, U.S.A.

The authors report the following potential conflicts of interest or sources of funding: D.M.S. reports other, Orthopediatrics; member of editorial or governing board, Springer. D.W.G. reports other, Arthrex, Pega Medical, Wolters Kluwer Health-Lippincott Williams $\theta$ Wilkins, Current Opinion in Pediatrics, AO Trauma International; board/committee member, AAOS, New York County Medical Society, New York State Society of Orthopedic Surgeons, PatelloFemoral Foundation, Pediatric Orthopaedic Society of North America, Pediatric Research in Sport Medicine. P.D.F. reports other, Orthopediatrics; editorial governing board, Clinical Orthopaedics and Related Research; board or committee member, Pediatric Orthopaedic Society of North America, Pediatric Research in Sports Medicine Society, Research in OsteoChondritis of the
}

patellar pole are also uncommon. ${ }^{4,5}$ They are often encountered in the pediatric population as sleeve fractures, in which a "sleeve" of cartilage and periosteum is separated from the inferior patellar pole, with or without subchondral bone., ${ }^{4,6}$ Like tibial tubercle avulsion fractures, patellar sleeve fractures are most common in males, with peak incidence at age 12.7 years. $^{7}$

Knee. Full ICMJE author disclosure forms are available for this article online, as supplementary material.

Received April 7, 2020; accepted August 19, 2020.

Address correspondence to Peter D. Fabricant, MD, MPH, Pediatric Orthopaedic Surgery Division, Hospital for Special Surgery, 535 East 70th St, New York, NY 10021,U.S.A. E-mail: fabricantp@hss.edu

(C) 2020 THE AUTHORS. Published by Elsevier Inc. on behalf of the Arthroscopy Association of North America. This is an open access article under the CC BY-NC-ND license (http://creativecommons.org/licenses/by-nc-nd/4.0/). 2666-061X/20464

https://doi.org/10.1016/j.asmr.2020.08.013 
Table 1. Summary of cases

\begin{tabular}{|c|c|c|c|c|c|}
\hline Characteristic & Case 1 & Case 2 & Case 3 & Case 4 & Case 5 \\
\hline$\overline{\text { Age }(y+m o)}$ & $12+5$ & $14+2$ & $12+10$ & $14+6$ & $11+2$ \\
\hline Sex & Male & Male & Male & Male & Female \\
\hline Cause of injury & Fell off scooter & Basketball & Soccer & $\begin{array}{l}\text { Jumped off subway } \\
\text { platform onto } \\
\text { tracks, slipped on } \\
\text { water }\end{array}$ & $\begin{array}{l}\text { Ran down stairs, } \\
\text { slipped and } \\
\text { landed on left leg }\end{array}$ \\
\hline Side of injury & Left & Left & Left & Right & Left \\
\hline Preoperative exam & $\begin{array}{l}\text { - Effusion, ecchymosis } \\
\text { - Unable to straight leg } \\
\text { raise or actively } \\
\text { extend knee }\end{array}$ & $\begin{array}{l}\text { - Effusion } \\
\text { - Tenderness at the } \\
\text { tibial tubercle and } \\
\text { distal pole of the } \\
\text { patella } \\
\text { - Unable to straight leg } \\
\text { raise }\end{array}$ & $\begin{array}{l}\text { - Effusion } \\
\text { - Tenderness at } \\
\text { proximal tibia } \\
\text { - } \text { ROM } 0^{\circ} \text { to } 20^{\circ} \\
\text { - Unable to straight } \\
\text { leg raise }\end{array}$ & 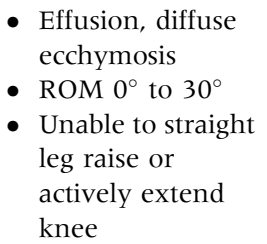 & $\begin{array}{l}\text { - Effusion } \\
\text { - } \text { ROM } 0^{\circ} \text { to } 20^{\circ} \\
\text { - Unable to straight } \\
\text { leg raise }\end{array}$ \\
\hline $\begin{array}{l}\text { History of } \\
\text { apophysitis }\end{array}$ & None known & None known & None known & $\begin{array}{l}\text { Osgood-Schlatter } \\
\text { disease }\end{array}$ & $\begin{array}{l}\text { Osgood-Schlatter } \\
\text { disease }\end{array}$ \\
\hline Proximal injury & $\begin{array}{l}\text { Sleeve avulsion fracture } \\
\text { of inferior patellar } \\
\text { pole (medial) }\end{array}$ & $\begin{array}{l}\text { Sleeve avulsion fracture } \\
\text { of inferior patellar } \\
\text { pole (medial) }\end{array}$ & $\begin{array}{l}\text { Avulsion fracture of } \\
\text { inferior patellar } \\
\text { pole (lateral } 20 \% \text { ) }\end{array}$ & $\begin{array}{l}\text { Sleeve avulsion } \\
\text { fracture of } \\
\text { inferior patella } \\
\text { pole (lateral } 20 \% \text { ) }\end{array}$ & $\begin{array}{l}\text { Avulsion fracture of } \\
\text { inferior patellar } \\
\text { pole (medial and } \\
\text { lateral) }\end{array}$ \\
\hline Distal injury & $\begin{array}{l}\text { Almost complete } \\
\text { patellar tendon } \\
\text { rupture with tibial } \\
\text { tubercle avulsion } \\
\text { fracture } 8 \mathrm{~mm}\end{array}$ & $\begin{array}{l}\text { Complete patellar } \\
\text { tendon rupture with } \\
\text { tibial tubercle } \\
\text { avulsion fracture }\end{array}$ & $\begin{array}{l}\text { Patellar tendon } \\
\text { rupture (medial } \\
80 \% \text { ) with small } \\
\text { tibial tubercle } \\
\text { avulsion fracture }\end{array}$ & $\begin{array}{l}\text { Patellar tendon } \\
\text { rupture (medial } \\
80 \% \text { ) with tibial } \\
\text { tubercle avulsion } \\
\text { fracture ( } 1 \mathrm{~cm} \\
\text { osseous/ } \\
\text { apophyseal } \\
\text { defect) and } \\
\text { subperiosteal } \\
\text { extension distally }\end{array}$ & $\begin{array}{l}\text { Tibial tubercle } \\
\text { avulsion fracture } \\
\text { from the } \\
\text { undersurface of } \\
\text { the patellar } \\
\text { tendon without } \\
\text { rupture of the } \\
\text { tendon }\end{array}$ \\
\hline \multicolumn{6}{|l|}{ Surgery } \\
\hline $\begin{array}{l}\text { Inferior pole of } \\
\text { patella }\end{array}$ & $\begin{array}{l}\text { Suture anchor with } \\
\text { heavy nonabsorbable } \\
\text { suture }\end{array}$ & $\begin{array}{l}\text { Suture anchor with } \\
\text { heavy nonabsorbable } \\
\text { suture }\end{array}$ & $\begin{array}{l}\text { Suture anchor with } \\
\text { heavy } \\
\text { nonabsorbable } \\
\text { suture }\end{array}$ & $\begin{array}{l}\text { Suture anchor with } \\
\text { heavy } \\
\text { nonabsorbable } \\
\text { suture }\end{array}$ & $\begin{array}{l}\text { Suture anchor with } \\
\text { heavy } \\
\text { nonabsorbable } \\
\text { suture }\end{array}$ \\
\hline Tibial footprint & $\begin{array}{l}\text { Double row suture } \\
\text { anchor repair with } \\
\text { heavy non- } \\
\text { absorbable suture } \\
\text { with Krakow stitch }\end{array}$ & $\begin{array}{l}\text { Double row suture } \\
\text { anchor repair with } \\
\text { heavy non- } \\
\text { absorbable suture } \\
\text { with Krakow stitch }\end{array}$ & $\begin{array}{l}\text { Double row suture } \\
\text { anchor repair } \\
\text { with heavy non- } \\
\text { absorbable suture } \\
\text { with Krakow } \\
\text { stitch }\end{array}$ & $\begin{array}{l}\text { Double row suture } \\
\text { anchor repair } \\
\text { with heavy non- } \\
\text { absorbable suture } \\
\text { with Krakow } \\
\text { stitch }\end{array}$ & $\begin{array}{l}\text { Double row suture } \\
\text { anchor repair } \\
\text { with heavy non- } \\
\text { absorbable suture } \\
\text { with Krakow } \\
\text { stitch }\end{array}$ \\
\hline $\begin{array}{l}\text { Final knee } \\
\text { function }\end{array}$ & $\begin{array}{l}\text { Full ROM, } 10^{\circ} \text { extensor } \\
\text { lag, RTA }\end{array}$ & Full ROM, AAT & $\begin{array}{l}\text { Full ROM, RTA, } \\
\text { patellofemoral } \\
\text { pain with activity } \\
\text { (resolved after } \\
\text { second surgery) }\end{array}$ & $\begin{array}{l}\text { Full ROM, AAT, } \\
\text { mild quad } \\
\text { atrophy }\end{array}$ & Full ROM, AAT \\
\hline $\begin{array}{l}\text { Length of follow- } \\
\qquad \text { up (mo) }\end{array}$ & 7.7 & 12.8 & 26.4 & 21.6 & 10.0 \\
\hline
\end{tabular}

AAT, activity as tolerated; ROM, range of motion; RTA, return to activity.

Combined bifocal patellar tendon avulsion fractures are exceedingly rare. To our knowledge, there are only 5 case reports of this injury in the literature. ${ }^{2,8-10}$ The purpose of this study was to highlight important diagnostic and treatment considerations in patients who present with bifocal patellar tendon avulsion fractures from the tibial tubercle and inferior patellar pole. We hypothesized that these bifocal injuries are best characterized with advanced imaging preoperatively and demonstrate satisfactory patient-reported outcomes after operative repair.

\section{Methods}

After institutional review board approval, a retrospective review was undertaken of clinical and radiologic data of 5 children who sustained bifocal patellar tendon avulsion fractures and presented for treatment at our urban tertiary-care orthopaedic facility from July 


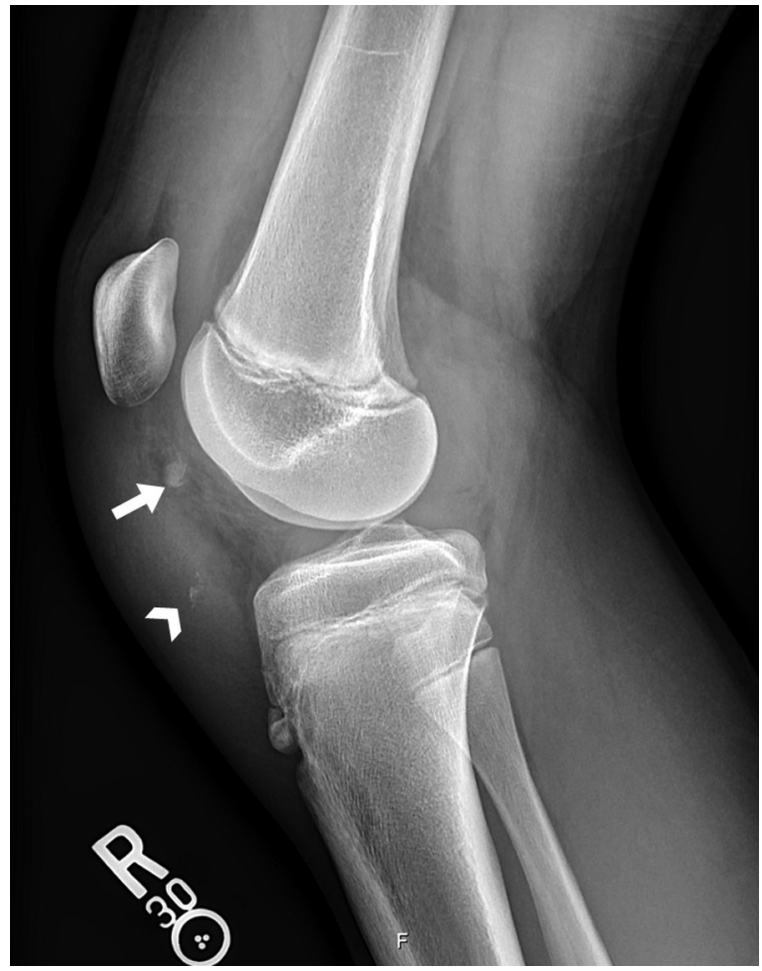

Fig 1. Case 4 preoperative $x$-ray (right knee). Preoperative lateral $x$-ray from case 4 demonstrates patella alta, an osseous fragment inferior to the patella (arrow), and a tiny focus of mineralization representing a subtle avulsion of the tibial tubercle with retraction (arrowhead).

2017 to February 2019 with $\geq 6$ months postoperative follow-up. The patients were managed and retrospectively identified by 3 senior orthopedic surgeons. Demographic data retrieved included age at time of injury/surgery, sex, side involved, mechanism of injury, length of follow-up, and the presence of previous apophyseal inflammation (e.g., Osgood-Schlatter disease [OSD], Sinding-Larsen-Johansson disease). Surgical technique and complications were reviewed. Patient-reported outcome measures were recorded preoperatively and at time of follow-up, including Hospital for Special Surgery Brief Functional Activity Scale (HSS Pedi-FABS), ${ }^{11}$ Patient-Reported Outcomes Measurement Information System (PROMIS) pain interference, PROMIS mobility, and Pediatric International Knee Documentation Committee Scale (PediIKDC). ${ }^{12,13}$ These patient-reported outcome measures are collected as standard of care at our institution and were reviewed retrospectively.

\section{Results}

Five children (4 male, 1 female), aged 11 to 14 years, presented with bifocal patellar tendon avulsion fractures between July 2017 and February 2018 (Table 1). Each child had open distal femoral and proximal tibial physes at the time of injury. Two patients had a history of OSD on the affected side.

In all cases, mechanism of injury was consistent with a sudden, forceful eccentric contracture of the quadriceps (Table 1). The patients sustained their injuries while playing basketball or soccer, falling off a motorized scooter, jumping on to subway tracks, and falling on the affected side after running down stairs. All patients presented with effusion of the affected knee and an inability to straight leg raise against gravity. Neurovascular examination was unremarkable, and
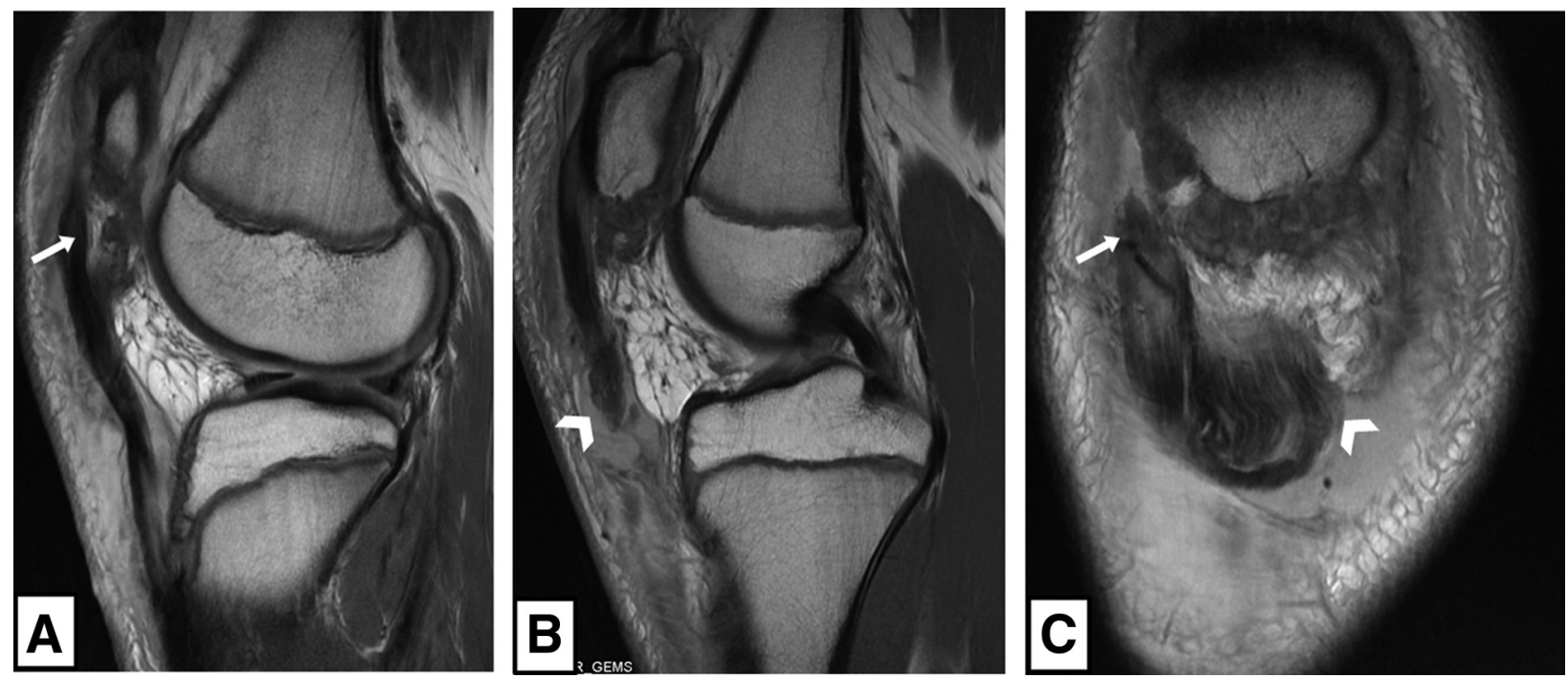

Fig 2. Case 4 preoperative magnetic resonance imaging (MRI) (right knee). Preoperative sagittal proton density MRI sequences from case 4 show proximal avulsion of the inferior patella laterally (A, arrow) and distal avulsion of the patellar tendon medially (B, arrowhead). This can also be seen on the coronal sequence, with lateral avulsion of the inferior pole of the patella (C, arrow) witandh proximal retraction of the medial patellar tendon due to discontinuity distally (C, arrowhead). 

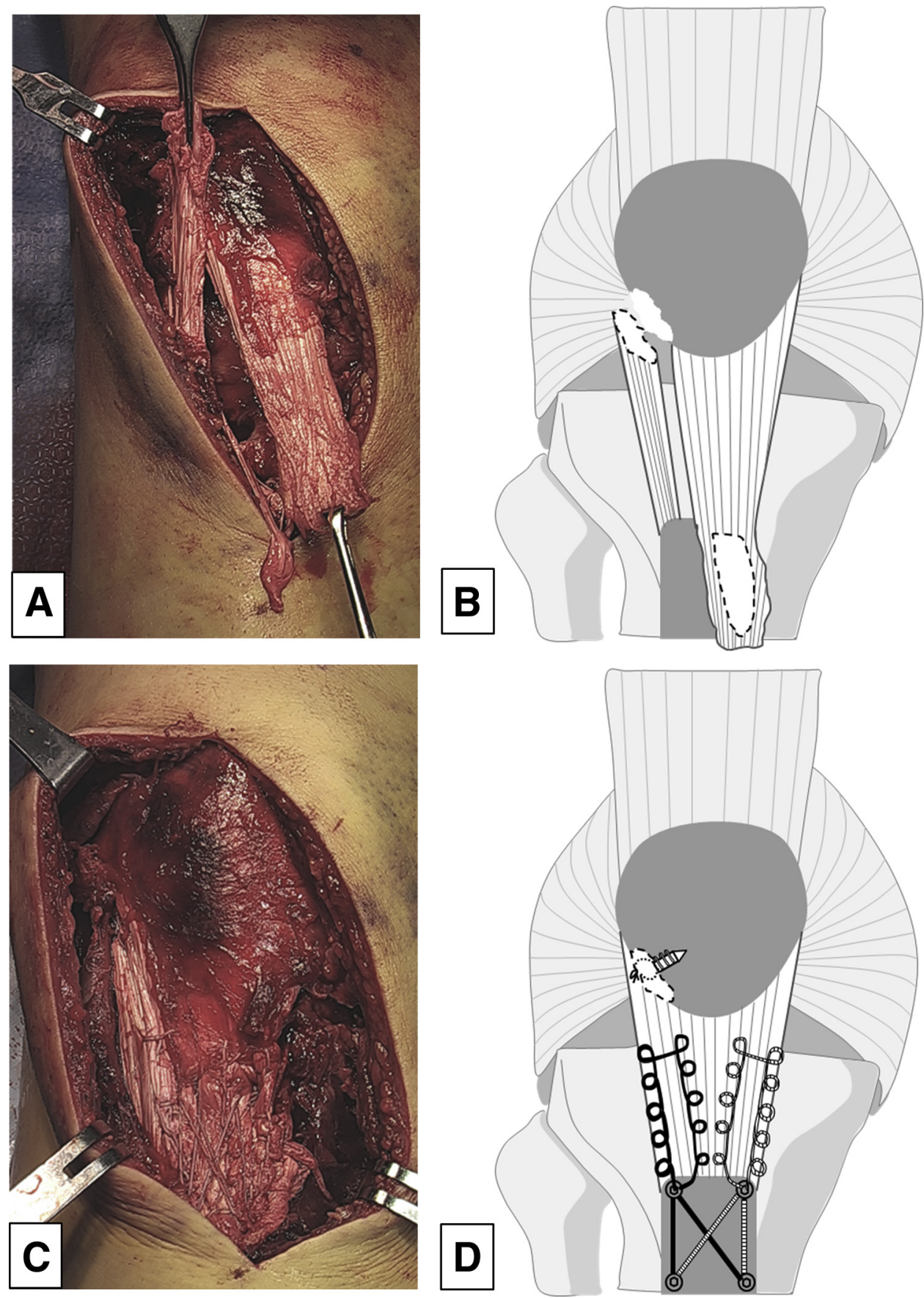

Fig 3. Intraoperative findings for case 4 (right knee). (A and B) The medial $80 \%$ of the distal footprint of the patellar tendon had peeled up subperiosteally, with an attached 1-cm apophyseal/ osseous defect from the tibial tubercle. Proximally, the inferior pole of the patella was fractured laterally in a separate periosteal sleeve avulsion fracture. (C and D) Repair of the distal patellar tendon was performed with a double-row suture anchor repair using heavy nonabsorbable suture. Proximally, the inferior pole fracture was repaired using a suture anchor with nonabsorbable suture. compartments were compressible during each preoperative consultation.

Preoperative $\mathrm{x}$-rays showed patella alta in all subjects, with median Caton-Deschamps index of 1.6 (range 1.4 to 1.8 ). Proximal injury was suspected by radiography in 4 cases $(1,2,4$, and 5$)$ because of the presence of additional avulsed fracture fragments noted at the inferior pole of the patella (Fig 1). In cases 3, 4, and 5, densities adjacent to the tibial tubercle were concerning for an avulsion fracture at the distal patellar tendon. In case 1 , advanced imaging was not pursued, and it was discovered only intraoperatively that the patellar tendon had almost completely avulsed from the tibial tubercle, with an 8$\mathrm{mm}$ osseous fragment. In all other cases, magnetic resonance imaging (MRI) correctly characterized the bifocal injuries and revealed the full extent of fractures and soft tissue injury (Fig 2).

Within 2 weeks of injury (median 6 days, range 2 to 13 days), each child was treated with open reduction and internal fixation using heavy nonabsorbable sutures secured with suture anchors (Table 1). The 
Table 2. Patient-reported outcome measures at final follow-up

\begin{tabular}{lccllr}
\hline Measure & Case 1 & Case 2 & Case 3 & Case 4 & Case 5 \\
\hline HSS Pedi-FABS & & & & & \\
$\quad$ Preoperative & - & 23 & 27 & 20 & - \\
$\quad$ Postoperative & 10 & 24 & 26 & 9 & 25 \\
PROMIS pain & & & & & \\
$\quad$ interference & & & & & \\
$\quad \begin{array}{l}\text { Preoperative } \\
\text { Postoperative }\end{array}$ & - & 62.22 & 63.56 & 62.28 & - \\
PROMIS mobility & - & 32.23 & 32.23 & 32.23 & 45.5 \\
$\quad \begin{array}{l}\text { Preoperative } \\
\text { Postoperative }\end{array}$ & 46.19 & 57.96 & 45.79 & 47.47 & 41.24 \\
Pedi-IKDC & & & & & \\
$\quad$ Preoperative & - & - & 23.67 & - & - \\
Postoperative & 89.13 & - & 80.43 & 89.13 & 66.3 \\
\hline
\end{tabular}

HSS Pedi-FABS, Hospital for Special Surgery Brief Functional Activity Scale; Pedi-IKDC, Pediatric International Knee Documentation Committee Scale; PROMIS, Patient-Reported Outcomes Measurement Information System.

-, data unavailable.

distal footprint was secured with a double-row suture anchor repair using a transosseous equivalent technique. Sutures from the proximal row anchors were secured to the tendon by running a Krakow stitch proximally and then distally back to the level of the proximal row. One suture from each anchor was then secured to each distal row anchor (Fig 3). One boy with a history of OSD had a particularly severe fracture pattern, with wide displacement and marked periosteal stripping (case 4 , Figs 1 to 3 ). The medial $80 \%$ of the distal footprint of his patellar tendon had peeled up subperiosteally, with an attached $1-\mathrm{cm}$ osseous defect from the tibial tubercle, and the lateral $20 \%$ of his patellar tendon was involved in a separate periosteal sleeve avulsion fracture from the inferior pole of the patella (Fig 3).

There were no intraoperative complications. Postoperatively, patients were immobilized in full extension, and range of motion was progressed at subsequent follow-up visits. Median length of follow-up was 12.8 months (range 7.7 to 26.4). All 5 patients obtained full range of motion of the affected knee. All had full extension of the knee except 1 (case 1, extension lag of $10^{\circ}$ ). One child (case 3) developed mild inferolateral pain around the patella with excessive physical activity and also sustained a soccer injury to the ipsilateral knee 18 months postoperatively. MRI showed chondromalacia and edema at the inferior patellar pole, with the patellar tendon remaining intact. He underwent a chondroplasty and scar debridement at the inferior patellar pole 2 years after primary patellar tendon repair. By 3 months after second surgery, the patient reported resolution of pain.

Patient-reported outcome measures are presented in Table 2. Three patients (cases 2, 3, and 4) had complete preoperative and postoperative PROMIS and HSS Pedi-FABS activity scores; all 3 had clinically relevant improvements in PROMIS pain $(29.99,31.33$, and 30.05) and PROMIS mobility $(30.84,29.25$, and 28.16) domains. Two of the 3 had no meaningful difference in preoperative and postoperative HSS PediFABS score $(-1$ and +1 points), indicating they had returned to a similar activity level as their preinjury state. ${ }^{11}$ One subject had a decrease of 11 points on the HSS Pedi-FABS activity scale but disclosed that he had discontinued organized sports and activities for reasons other than the injured knee. Four of 5 subjects reported a postoperative Pedi-IKDC score at final follow-up; median score for the cohort was 84.8 points, which is not statistically different from the median population normative value of $94.6(P=.07,1$-sample Wilcoxon signed rank test).

\section{Discussion}

This study highlights that bifocal avulsion fractures of the tibial apophysis and inferior patellar pole are best characterized with advanced imaging preoperatively and demonstrate satisfactory functional and patientreported outcomes after operative repair. Only a handful of reported cases of this injury pattern are found in the orthopedic literature. ${ }^{2,8-10}$ A high index of suspicion and sufficient diagnostic imaging are keys to successful treatment.

The patients in this case series were ages 11 to 14 years and predominantly male. This demographic is consistent with the literature on these injuries: the mean age of tibial tubercle avulsion fractures has been reported to be 14.6 years, ${ }^{1}$ and peak incidence of patellar sleeve fractures occurs at age 12.7 years. ${ }^{4,7}$ In a recent systematic review of tibial tubercle avulsion fractures, $97 \%$ of patients were male, and $42 \%$ were playing basketball, the most commonly reported mechanism of injury. ${ }^{1}$ All patients in this case series described a history consistent with eccentric load placed on the knee. Two specifically reported a jumping mechanism at time of injury, one of whom was playing basketball. Additionally, 2 of the 5 patients in this retrospective review had a history of OSD. OSD and Sinding-Larsen-Johansson syndrome have been associated with avulsion-type fractures at the knee, with a $23 \%$ incidence of OSD among patients with tibial tubercle avulsion fractures. ${ }^{1,2,6}$ It has been postulated that repetitive traction and inflammation at the tibial tubercle predisposes to an avulsion-type injury. ${ }^{14}$

A number of classification systems for tibial tubercle fractures have been proposed. Watson-Jones ${ }^{15}$ first categorized these fractures into 3 types, and Ogden et al. ${ }^{14}$ introduced 2 subdivisions on the basis of fragment displacement. Numerous additions to the Watson-Jones classification have since been made 
based on the identification of additional fracture patterns. ${ }^{3,6,16}$ Type III fractures, coronal fractures that extend posteriorly to cross the primary ossification center, are most common. ${ }^{1}$ In this series, all patients had distal type 1 fractures limited to the tibial tubercle with avulsion of the patellar ligament, first described by Frankl et al. ${ }^{17}$ in 1990.

In the setting of traumatic pediatric knee injuries, first-line diagnostic modality is often radiography, but the full extent of a periosteal sleeve fracture can be difficult to appreciate without MRI. Bates et al. ${ }^{18}$ demonstrated the utility of MRI in evaluating the extent of injury and displacement of patellar sleeve fractures. In case 1 of this series, plain radiography showed mineralization over the inferior margin of the patellofemoral joint, as well as nonspecific mild irregularity of the tibial tubercle. However, the bifocal nature of this injury was discovered only intraoperatively. This case highlights the value of obtaining MRI as a clarifying imaging modality in the setting of tibial tubercle or patellar sleeve avulsions, as an injury of the tibial tubercle or patella does not eliminate the chance of concomitant injury of the other. This can be best appreciated in skeletally immature patients on MRI.

Management of bifocal patellar tendon avulsion fractures warrants open anatomic reduction and fixation, which can be challenging owing to the lack of a large bony fragment. Small avulsed osseous fragments can therefore be fixed with heavy sutures secured with suture anchors. No major complications were reported in this series. However, limb-length discrepancy and recurvatum have historically been reported in $5 \%$ and $4 \%$ of tibial tubercle avulsion fractures, respectively, and follow-up for $\geq 2$ years or until skeletal maturity is warranted. ${ }^{l}$ Patients had good functional outcomes on clinical exam and validated patient-reported outcome measures.

\section{Limitations}

This study has several limitations that should be noted. First, this is a retrospective study from a single North American orthopedic facility and may not be generalizable to all populations. Second, this case series reports on only 5 patients. However, bifocal patellar tendon avulsion fractures are rare injuries, and this series will supplement the limited literature on this topic. $^{2,8-10}$ Third, postoperative follow-up ranged from 7.7 to 26.4 months, and most patients had not reached skeletal maturity. Potential complications such as leg length discrepancy and recurvatum may not yet be evident in these patients. However, the aim of this study was to highlight the importance of advanced imaging for diagnosis and demonstrate satisfactory patient-reported outcomes after operative repair, which was achieved with minimum 6-month follow-up.
Finally, we do not directly compare bifocal injuries to unifocal injuries of the extensor mechanism, which could further highlight potential risk factors and aspects of recovery unique to the bifocal injury pattern. This case series was primarily descriptive, and such a comparison was outside its scope.

\section{Conclusion}

Advanced imaging (e.g., MRI) is required to understand the full extent of injury and should be obtained in the setting of traumatic patella alta to evaluate for the presence of a bifocal lesion and plan surgical intervention accordingly. These patients demonstrated satisfactory functional and patient-reported outcomes after operative repair.

\section{References}

1. Pretell-Mazzini J, Kelly DM, Sawyer JR, et al. Outcomes and complications of tibial tubercle fractures in pediatric patients: A systematic review of the literature. J Pediatr Orthop 2016;36:440-446.

2. Bradko V, Stoll WT, Haruno LS, Rosenfeld SB, McKay SD. Two cases of combined patellar tendon avulsion from the tibia and patella. SICOT-J 2018;4:17.

3. Mckoy BE, Stanitski CL. Acute tibial tubercle avulsion fractures. Orthop Clin North Am 2003;34:397-403.

4. Hunt DM, Somashekar N. A review of sleeve fractures of the patella in children. Knee 2005;12:3-7.

5. Dai LY, Zhang WM. Fractures of the patella in children. Knee Surg Sports Traumatol Arthrosc 1999;7:243-245.

6. Davidson D, Letts M. Partial sleeve fractures of the tibia in children: An unusual fracture pattern. J Pediatr Orthop 2002;22:36-40.

7. Ray JM, Hendrix J. Incidence, mechanism of injury, and treatment of fractures of the patella in children. J Trauma 1992;32:464-467.

8. Clarke DO, Franklin SA, Wright DE. Avulsion fracture of the tibial tubercle associated with patellar tendon avulsion. Orthopedics 2016;39:e561-e564.

9. Stepanovich MT, Slakey JB. Combined tibial tubercle avulsion fracture and patellar avulsion fracture: An unusual variant in an adolescent patient. Am J Orthop (Belle Mead NJ) 2016;45:E31-E34.

10. Hermansen LL, Freund KG. Bifocal osseous avulsion of the patellar tendon from the distal patella and tibial tuberosity in a child. Knee Surg Sports Traumatol Arthrosc 2016;24:712-714.

11. Fabricant PD, Robles A, Downey-Zayas T, et al. Development and validation of a pediatric sports activity rating scale: The Hospital for Special Surgery Pediatric Functional Activity Brief Scale (HSS Pedi-FABS). Am J Sports Med 2013;41:2421-2429.

12. Kocher MS, Smith JT, Iversen MD, et al. Reliability, validity, and responsiveness of a modified International Knee Documentation Committee subjective knee form (Pedi-IKDC) in children with knee disorders. Am J Sports Med 2011;39:933-939.

13. Nasreddine AY, Connell PL, Kalish LA, et al. The Pediatric International Knee Documentation Committee (Pedi-IKDC) 
subjective knee evaluation form. Am J Sports Med 2017;45: 527-534.

14. Ogden JA, Tross RB, Murphy MJ. Fractures of the tibial tuberosity in adolescents. J Bone Joint Surg Am 1980;62: 205-215.

15. Watson-Jones R. Fractures and joint injuries. Baltimore: Williams and Wilkins Company, 1955.

16. Ryu RK, Debenham JO. An unusual avulsion fracture of the proximal tibial epiphysis. Case report and proposed addition to the Watson-Jones classification. Clin Orthop Relat Res 1985;194:181-184.

17. Frankl U, Wasilewski SA, Healy WL. Avulsion fracture of the tibial tubercle with avulsion of the patellar ligament. Report of two cases. J Bone Joint Surg Am 1990;72: $1411-1413$.

18. Bates DG, Hresko MT, Jaramillo D. Patellar sleeve fracture: Demonstration with MR imaging. Radiology 1994;193: 825-827. 